\title{
25 Research Suare \\ Cinnabarinic Acid from Trametes Coccinea Fruiting Bodies Exhibits Antibacterial Activity Through Inhibiting the Biofilm Formation
}

\section{Merilin Kakoti}

Gauhati University

\section{Samim Dullah}

Assam Agricultural University

Dibya Jyoti Hazarika

Assam Agricultural University

\section{Madhumita Barooah}

Assam Agricultural University

Robin Chandra Boro ( $\nabla$ robin.boro@aau.ac.in )

Assam Agricultural University https://orcid.org/0000-0002-0866-3357

\section{Research Article}

Keywords: Antimicrobial, Bioactive metabolites, Biofilm formation, Cinnabarinic acid, Trametes coccinea

Posted Date: September 16th, 2021

DOl: https://doi.org/10.21203/rs.3.rs-876241/v1

License: (c) (i) This work is licensed under a Creative Commons Attribution 4.0 International License.

Read Full License

Version of Record: A version of this preprint was published at Archives of Microbiology on February 15th, 2022. See the published version at https://doi.org/10.1007/s00203-022-02782-4. 


\section{Abstract}

Wild mushrooms are rich sources of natural compounds with potent bioactive properties. Several important metabolites have been reported from mushrooms, which possess clinically important bioactive properties like antibacterial activity, anticancer activity, antidiabetic activity and antioxidant activity. In this study, we have evaluated the antimicrobial activity of Trametes coccinea fruiting body extracts against different bacterial isolates viz. Bacillus subtilis, Bacillus cereus and Escherichia coli. Fruiting bodies of three T. coccinea samples, of which two were collected from Santipur, Arunachal Pradesh and one collected from Jorhat, Assam, were used for extraction using methanol. The extracts showed potent antimicrobial activity against all the test bacteria. Minimum Inhibitory Concentration (MIC) of the extracts against Bacillus subtilis, Bacillus cereus and Escherichia coli was recorded as $400 \mu \mathrm{g} / \mathrm{ml}, 400 \mu \mathrm{g} / \mathrm{ml}$ and $300 \mu \mathrm{g} / \mathrm{ml}$ respectively. Further, the bioactive compounds of the extract were separated and detected using Thin Layer Chromatography (TLC). Presence of Cinnabarinic acid (CBA), a potent antimicrobial compound was detected in TLC, which was further confirmed through High Performance Liquid Chromatography (HPLC) and Electrospray Ionization-Mass Spectrometry (ESI-MS). Cinnabarinic acid was able to inhibit the formation of biofilms in Bacillus subtilis and $B$. cereus, suggesting that the compound can be beneficial in the management of biofilm based antimicrobial resistance.

\section{Introduction}

Antibiotics have gained place among the most important medical interventions needed for the treatment of complex clinical causalities. Till the discovery of penicillin in 1929, several antibiotics have come into the scenario for combating infectious diseases (Smânia et al. 1995). However, many of the antibiotics have failed to serve in persistent manner because of resistance mechanisms employed by several pathogenic bacteria. These mechanisms include enzymatic degradation or alteration of antibiotic molecules, mutational changes of the antibiotic target sites, decreased permeability of antibiotics inside the cells, efflux of antibiotic molecules from the cells, formation of protective layer such as biofilm and many others (Munita and Arias 2016). Biofilm formation is one of the most effective and wide spread mechanisms used by several Gram-positive and Gram-negative bacteria to show resistance against common antibiotics. This mode of defense mechanism is associated with the chronic infections with their inherent resistance to antibiotic chemotherapy (Stewart and William Costerton 2001; Høiby et al. 2010). Therefore, investigations of new antimicrobials that can work for the inhibition of biofilm formations is becoming a needful strategy to combat antibiotic resistance in clinical cases.

Natural products from different natural sources such as microbes, plants and animals have played a significant role in doubling the human life span during the 20th century. Besides the use of wild mushrooms as nutritive food stuffs since ancient time, (Sharma and Gautam 2015), they have been a prime source of attraction due to their potential for biosynthesis of various secondary metabolites in their fruiting bodies. Many of these metabolites serve as bioactive components with many medicinal properties. Several important metabolites have been reported from mushrooms having different bioactive properties. Some of them are clinically proven to exhibit significant bioactive properties. For instance, 
ganodermin and rufuslactone have been found to show potent antifungal properties (Luo et al. 2005; Wang and $\mathrm{Ng}$ 2006). Other bioactive metabolites from higher fungi includes ganoderic acid $\mathrm{T}$, ganoderic acid $\mathrm{F}$ (antimetastatic effect), ganoderic acid Me (Anti-metastatic effect, reduce tumor invasion), ganoderic acid DM (anti-proliferative effect), lucidenic acid $\mathrm{N}$, lucialdehyde $\mathrm{B}$, lucialdehyde $\mathrm{C}$ (anticancer activity), 11ß-Hydroxy-3,7-dioxo-5a-lanosta8,24(E)-dien-26-oic acid (Cytotoxic effect), Cortinellin (antibacterial, antifungal), sesquiterpenoid and hydroquinones (antibacterial activity), transcinnamic acid, photocattheuric acid, caffeic acid, gallic acid, ascorbic acid and benzoic acid (antioxidant activity) (Herrmann 1962; Wu et al. 2001, 2012; Gao et al. 2002; Tang et al. 2006; Dembitsky and Maoka 2007; Chen et al. 2008; Zhong and Xiao 2009; Xu et al. 2010; De Silva et al. 2013; Kozarski et al. 2015).

Trametes coccinea (also known as Pycnoporus coccineus), is one of the white-rot fungus (Basidiomycetes) belonging to the family Polyporaceae and the class Agaricomycetes of fungi, which most commonly grows in the outer layer of decaying woods and also found on the surface of deciduous trees (Zhang et al. 2020). This mushroom produces brightred colour pigments, which is deposited in the fruiting bodies. Few other species of Trametes including T. sanguinea, T. cinnabarina and T. punicea also produce this type of pigments (Eggert 1997) (Téllez-Téllez et al. 2016). Few studies have characterized the pigments from T. cinnabarina (synonym. P. cinnabarinus) for their bioactive properties including the antibacterial activity. Cinnabarinic acid, cinnabarin, tramesanguine and few other phenoxazinone derivatives were characterized as bioactive metabolites of T. cinabarina and T. sanguinea (Sullivan and Henry 1971; Eggert et al. 1996; Téllez-Téllez et al. 2016). However, scarce information is available for bioactive properties of metabolites isolated from T. coccinea. In this study, the pigmented fruiting body extracts of three $T$. coccinea samples were used to determine the antibacterial activity against Bacillus subtilis, B. cereus and Escherichia coli. The active metabolites were also characterized using analytical chromatographic techniques.

\section{Materials And Methods}

\section{Microorganisms and culture condition:}

The bacterial isolates used in this study viz. Bacillus subtilis SCB-1 (Accession no MF893336.1), Bacillus cereus S6 (Accession no MF187565.1) , and Escherichia coli K-12, were obtained from the Microbial Technology Laboratory, Department of Agricultural Biotechnology, Assam Agricultural University, Jorhat, Assam. All the test bacterial strains were regularly sub-cultured on Nutrient Agar (NA) medium (Himedia, India) for further use and maintenance.

\section{Source material:}

Fruiting bodies of three mushroom samples belonging to Trametes coccinea were used in this study. Fresh fruiting bodies of two samples of Trametes coccinea APS1 (GenBank Accession Number MK851556.1) and T. coccinea APS2 (GenBank Accession Number MK851557.1) were collected from Santipur, Arunachal Pradesh. Another sample T. coccinea F3 (GenBank Accession Number MK168589.1) 
was collected from Jorhat, Assam. Samples were identified based on their morphology and molecular data of ribosomal RNA internal transcribed spacer (ITS) region (Dullah et al. 2021; Kakoti et al. 2021).

\section{Preparation of Extracts:}

For extraction of pigments from fruiting bodies, the samples were cut into small pieces and dried in a hot air oven at $45^{\circ} \mathrm{C}$ for $6 \mathrm{~h}$. Dry samples were powdered using an electric grinder and sieved through a 0.5 $\mathrm{mm}$ sieving net. A $1 \mathrm{~g}$ of fruiting body powder was extracted with $20 \mathrm{ml}$ of methanol and supernatant was collected through centrifugation at $6,000 \mathrm{rpm}$ for $15 \mathrm{~min}$. The residue was re-extracted twice with another $20 \mathrm{ml}$ of methanol each time. The supernatant thus obtained were filtered through a $0.22 \mu \mathrm{m}$ syringe filter (GE Healthcare, USA) and dried under vacuum. The concentrated extract was re-dissolved in dimethyl sulphoxide (DMSO) or acetonitrile at specific concentrations as per the further requirements.

\section{Evaluation of Antibacterial activity:}

The DMSO solubilized methanol extracts of the samples were prepared at different concentrations viz: $1000,500,250,125,100,75,50$ and $25 \mu \mathrm{g} / \mathrm{ml}$ for the assessment of antibacterial activity. Well diffusion method was employed to study the inhibitory activity against 3 bacterial strains mentioned earlier. The bacterial strains were pre-grown in Nutrient Broth (NB) medium till $\mathrm{OD}_{600}$ of 1.0 and spread on to $90 \mathrm{~mm}$ Petri plates containing Mueller Hinton Agar (MHA). Wells were made ( $5 \mathrm{~mm}$ diameter) using a sterile well borer. Extracts at aforesaid concentrations were loaded into the respective wells of the plates. DMSO was used as negative control. Streptomycin $(100 \mu \mathrm{g} / \mathrm{ml})$ was considered as positive reference and tested against each bacterial strain in the similar way as the samples. The plates were incubated at $30^{\circ} \mathrm{C}$ for 16 h. The presence of zone of inhibition around the wells indicated the positive antibacterial activity. The minimum concentrations at which the extracts showed detectable zone of inhibition was considered as minimum zone-forming concentration. The experiment was performed with three biological replicates for each bacterial strain.

\section{Determination of Minimum Inhibitory Concentration (MIC):}

The Minimum Inhibitory concentrations were determined using the microdilution method in Luria Bertani (LB) broth. A $0.5 \mathrm{McF}$ arland scale inoculum of each bacterial strain was prepared from $24 \mathrm{~h}$ old suspension culture. Mushroom extracts at different concentrations were prepared and tested against the three bacterial isolates. The $5 \mathrm{ml}$ culture broth consisted of $4.4 \mathrm{ml}$ sterile LB broth, $0.1 \mathrm{ml}$ standardized bacterial suspension culture and $0.5 \mathrm{ml}$ extract (with final concentrations in the range between $50-1000$ $\mu \mathrm{g} / \mathrm{ml}$ ). The initial absorbance was noted at $600 \mathrm{~nm}$ and the culture tubes were incubated at $37^{\circ} \mathrm{C}$ for 16 $\mathrm{h}$ with shaking followed by recording the final absorbance at the same spectrophotometric condition. MIC was determined as the last dilution of extract at and above which $>90 \%$ inhibition of bacterial proliferation was recorded.

Metabolite production in solid culture medium: 
The in-vitro mycelial cultures of the mushroom samples were generated by inoculating on to potato dextrose agar (PDA) plates, which were then maintained at $28^{\circ} \mathrm{C}$ for 7 days. Production of the red pigment was optimized in PDA medium supplemented with different concentrations of $(0.005 \%, 0.01 \%$ and $0.015 \%$ ) guaiacol. Extraction of the pigment from the in-vitro culture plate of mushrooms was carried out by taking out the freshly grown mycelia from PDA plates in a conical flask containing $20 \mathrm{ml}$ of methanol, followed by continuous shaking for $4 \mathrm{~h}$, which was then sonicated at maximum intensity for 5 min. The pellet was separated through centrifugation and re-extracted twice with another $20 \mathrm{ml}$ of methanol each time. The supernatant was processed to obtain the crude extract as described earlier.

\section{Detection and identification of metabolites:}

The crude extract of each mushroom sample was further separated in a silica gel thin layer chromatography (TLC) plate using benzene: ethyl acetate: glacial acetic acid (12: 6:2) as mobile phase. Presence of cinnabarinic acid and phenoxazine, two important metabolites of $T$. coccinea were detected in TLC using commercial standards (Sigma, USA). The $\mathrm{R}_{\mathrm{f}}$ values were calculated from the TLC chromatogram. The fractions containing cinnabarinic acid and phenoxazine were extracted from the TLC plate and re-dissolved in acetonitrile for further analysis. The absorption spectrum of the purified fraction was generated using an Evolution 202 UV-Visible spectrophotometer (Thermo Scientific, USA). Bioactivity of the TLC fraction were assessed against Bacillus subtilis, B. cereus and Escherichia coli as described earlier.

Further, the crude extracts and purified bioactive fraction were loaded onto a Cosmosil C18 column using the auto sampler of Hitachi Chromaster HPLC system. The samples were eluted with the mobile phase containing $2.5 \%$ acetic acid in water $(A)$ and acetonitrile $(B)$ in a gradient mode. The gradient profile was as follows: $20 \%$ B at $0-5 \mathrm{~min}, 50 \%$ B at $10 \mathrm{~min}, 80 \%$ B at $15 \mathrm{~min}$, continued with $80 \%$ B till $23 \mathrm{~min}, 20 \%$ B at $25 \mathrm{~min}$ and continued till $30 \mathrm{~min}$. The cinnabarinic acid and phenoxazine were used as standards, and the peaks were detected using a diode array detector in a scan mode from $200-400 \mathrm{~nm}$. The identity of cinnabarinic acid and phenoxazine corresponding fractions were further confirmed by LC-ESI-MS using the same chromatographic parameters. Mass of each compound was analyzed based on positive mode of ionization.

\section{Biofilm inhibition assay:}

The inhibition of biofilm in Bacillus subtilis and B. cereus was assessed in presence of different concentrations of bioactive pigment. The bacterial cells were grown in liquid medium till $\mathrm{OD}_{600} 1.0$ at 30 ${ }^{\circ} \mathrm{C}$. A $10 \mu \mathrm{l}$ of culture was added to different wells of a sterile 96 wells microtiter plate. $170 \mu \mathrm{l}$ of fresh liquid broth was added to each well containing bacterial culture. The TLC purified active fraction (20 $\mu$ l) prepared in DMSO were added at different concentrations. Instead of extracts, DMSO was used in the control wells. The plates were incubated at $30^{\circ} \mathrm{C}$ for $24 \mathrm{~h}$. The plates were stained with $250 \mu \mathrm{l}$ of $0.1 \%$ crystal violet and biofilm production was estimated as described previously (O'Toole 2011). 


\section{Results And Discussion}

\section{Antibacterial activity of $T$. coccinea extracts:}

Trametes coccinea, synonym Pycnoporus coccineus, is a saprophytic white rod fungus belonging to the family Polyporaceae. This species, and the related members of this genera are characterized by the presence of an annual sessile or effused-reflexed basiodiocarp which is often pigmented (Lomascolo et al. 2011). Four species of this genus namely Pycnoporus cinnabarinus, $P$. sanguineus, $P$. coccineus and $P$. puniceus were found to produce a typical red pigment which is deposited in the fruiting bodies, and due to this the fruiting body turns in to orange in colour. Except this characteristic feature, the rest of all morphological characters of the genus are similar to the genus Trametes, and therefore recent taxonomy have included these four species in to the genus Trametes (Welti et al. 2012).

In this study, the red pigment was isolated as crude extract using methanol. Here, the antibacterial activity of Trametes coccinea fruiting body extract was assessed against two Gram-positive bacteria viz. Bacillus subtilis and Bacillus cereus and one Gram- negative bacteria viz. Escherichia coli. The extract showed potent inhibitory activity against the tested bacterial strains. The extracts of three mushroom samples were able to form visible zones of inhibition, as detected in the Mueller Hinton Agar plates. The photographs of plates showing zones of inhibition against the bacterial strains were shown in Fig. 1. However, the diameter of the zones of inhibition of the crude extracts at a concentration of $1000 \mu \mathrm{g} / \mathrm{ml}$ was smaller than that of pure streptomycin $(100 \mu \mathrm{g} / \mathrm{ml})$, the positive control used in this study. The minimum zone forming concentrations of the three extracts against Bacillus subtilis, $B$. cereus and $E$. coli are presented in Table 1. It was also observed that the extracts were effective at lower concentrations against Gram- negative bacteria ( $E$. coli) than the Gram- positive bacterial strains ( $B$. subtilis and $B$. cereus). Although, the three tested mushroom samples were collected from different places but, a very negligible amount of differences were recorded in the minimum zone forming concentrations among all the three mushroom extracts. From this, it could be concluded that the active compound(s) present in the extracts of different samples of same species is same and present in similar concentrations.

The MIC of the three extracts were also evaluated in the liquid culture against the test bacteria, which revealed that, the extracts could inhibit more than $90 \%$ of bacterial growth at a concentration of 400 $\mu \mathrm{g} / \mathrm{ml}$ against $B$. subtilis and $B$. cereus. Similarly, the growth of $E$. coli was also inhibited by more than $90 \%$ at a concentration of $300 \mu \mathrm{g} / \mathrm{ml}$ of extracts (Fig. 2). It was earlier reported that the red pigments from Pycnoporus cinnabarinus (synonym. Trametes cinnabarina), an evolutionary close species to Trametes coccinea, possess antibacterial properties against Bacillus subtilis, Escherichia coli, Klebsiella pneumonae, Salmonella enteritidis, Staphylococcus aureus and Streptococcus spp. The MIC of $P$. cinnabarinus extracts against these bacterial strains was recorded between $0.02-0.7 \mathrm{mg} / \mathrm{ml}$ (Eggert 1997). The pigments of Pycnoporus cinnabarinus has been reported to contain a major bioactive compound called as cinnabarinic acid, along with few analogues of this compound (Eggert et al. 1995; Eggert 1997). Cinnabarinic acid is a metabolite of the kynurenine pathway, which derives from two molecules of 3-hydroxyanthranilic acid through a condensation reaction (Fazio et al. 2012). Laccase 
mediated production of the red pigments by mycelial cultures of Pycnoporus cinnabarinus has been established earlier (Eggert et al. 1995). Laccase catalyzes the oxidative dimerization of 3-

hydroxyanthranilic acid in a 6-electron oxidation reaction (Eggert 1997). Our findings also suggested the production of similar pigments in the mycelial cultures of $T$. coccinea (Supplementary Figure S1). It was further confirmed in our study that supplementation of guaiacol (an inducer for laccase production) enhances the pigment production in mycelial cultures, suggesting the involvement of laccase in the synthesis process. This enables an advantageous biosynthesis of cinnabarinic acid over chemical synthesis where hazardous or expensive catalysts are used thereby making the synthesis process nonrenewable and environmentally unfriendly (Jabri and Overman 2013). Recently, herterologous production of cinnabarinic acid has been described in a metabolically engineered Pseudomonas chlororaphis GP72 (Yue et al. 2019).

\section{Detection and identification of bioactive metabolite:}

Cinnabarinic acid, a red pigmented derivative belonging to the group of phenoxazinone, is produced by a few Tramates (Pycnoporus) species as a byproduct of kynurenine pathway, due to the condensation of two molecules of 3-hydroxyanthranilic acid (Téllez-Téllez et al. 2016). To confirm the presence of cinnabarinic acid and/or its analogues, the crude extracts of the mushroom fruiting bodies were separated in a TLC plate containing silica gel as stationary matrix. It was observed that the crude extract of sample APS 1 was separated to 5 different fractions with $R_{f}$ values of $0.91,0.83,0.74,0.65$ and 0.32 (Fig. 3A). Likewise, APS2 and F3 showed 5 fractions $(0.85,0.75,0.65,0.33$ and 0.17$)$ and 6 fractions $(0.85,0.75,0.65,0.56,0.33$ and 0.25$)$, respectively (Fig. $3 B$ and C). The fractions with $R_{f}$ value 0.56 and 0.25 were exclusively detected in the sample $F 3$, whereas, fractions with $R_{f}$ value 0.17 was exclusive to sample APS2. While comparing with the standards of cinnabarinic acid (Sigma, USA) and phenoxazine (Sigma, USA), both the fractions were detected in sample APS1, APS2 and F3, suggesting that the two compounds were common active metabolites of the T. coccinea. As cinnabarinic acid has been reported from other related species of $T$. coccinea that possess antibacterial activity (Eggert 1997), we assumed that this compound is responsible for the inhibitory activity against the Gram-positive and Gram-negative test bacterial strains. To confirm this, we tested the antibacterial activity of the major fractions in each sample after TLC separation. It was found that the cinnabarinic acid corresponding fraction contained significant antibacterial activity against the test bacterial strains (Supplementary Table S1).

Spectroscopic analysis suggested that this fraction has an absorption maxima of $427 \mathrm{~nm}$ in the visible region of the spectrum (Supplementary Fig. S2).

To confirm the identity of cinnabarinic acid, we also considered the HPLC and ESI-MS data as evidence. The HPLC analysis revealed the presence of cinnabarinic acid in the crude as well as TLC purified fraction, with a retention time of $14.1 \mathrm{~min}$. The HPLC peaks of standards cinnabarinic acid (Sigma, USA) and phenoxazine (Sigma, USA), T. coccinea crude extracts from sample APS1 and APS2, along with TLC purified bioactive fraction $\left(R_{f}\right.$ value 0.33$)$ are shown in Fig. 4. The molecular mass of cinnabarinic acid from T. coccinea was detected using ESI-MS which suggested the presence of cinnabarinic acid [m/ $\mathrm{z}$ : 
$\left.301.0(\mathrm{M}+\mathrm{H})^{+}\right]$in the TLC purified fraction (Fig. 5A). The identity of phenoxazine present in the samples as common metabolites (TLC $R_{f}$ value $0.83 / 0.85$ ) was also confirmed by ESI-MS [m/z: $184.1(\mathrm{M}+\mathrm{H})^{+}$] (Fig. 5B), however, this fraction did not possess antibacterial activity.

\section{Inhibition of biofilm production in Bacillus subtilis and B. cereus.}

Biofilm production is an important mechanism of antimicrobial resistance in many pathogenic bacteria. Biofilm production in bacteria is associated with several economic and environmental implications as well as medical complications. Recent strategies to overcome these problems focus on the use of antimicrobial agents that could target bacterial biofilm formation (Singh et al. 2017). Here, we performed the biofilm production assay to study the effect of cinnabarinic acid produced by $T$. coccinea on development of bacterial biofilms in B. subtilis and B. cereus. It was observed that a concentration of 500 $\mu \mathrm{g} / \mathrm{ml}$, cinnabarinic acid from APS1, APS2 and F3 could inhibit $95 \%, 87.7 \%$ and $86.9 \%$ of biofilm formation, respective in $B$. subtilis compared to the control condition. Similarly, the same concentration was also found to be effective to inhibit (91.5 - 94.7\%) biofilm formation in B. cereus (Fig. 6). Previously, a few natural compounds including bacterial and fungal metabolites have been reported to inhibit bacterial and fungal biofilms. For example, farnesol - a sesquiterpene group of quorum sensing molecule from Candida species was reported to inhibit biofilm formation in Staphylococcus epidermidis, and pathogenic strains of Candida albicans (Ramage et al. 2002). In a separate study, it was that farnesol treatment could reverse the resistance of methicillin-resistant Staphylococcus aureus against methicillin by inhibition of biofilm production (Gomes et al. 2009). Similarly, bacterial pigment prodigiosin (an alkaloid) could inhibit biofilm production in Pseudomonas aeruginosa (Kimyon et al. 2016). There are several possibilities through which biofilm production is inhibited. Some antibiotics targets bacterial exopolysaccharide production mechanisms, thereby inhibiting the biofilm production. A few antibacterial compounds (for e.g., prodigiosin) targets bacterial DNA of the target cells and induce reactive oxygen species (ROS) production, which ultimately leads to the inhibition of bacterial biofilm production and cell death (Kimyon et al. 2016). Prodigiosin also cause damages to the plasma membrane of Gram-positive bacteria and show antimicrobial properties (Suryawanshi et al. 2017). It was reported earlier that cinnabarinic acid generated from the oxidation of 3-hydroxyanthranilic acid induced apoptosis in thymocytes of mouse through the production of ROS and DNA fragmentation (Hiramatsu et al. 2008). There is a strong possibility that cinnabarinic acid may use any of these mechanisms to exhibit antibacterial activity and inhibit bacterial biofilm formation.

\section{Conclusion}

We established the in-vitro antibacterial activity of the fruiting body extracts of Trametes coccinea, a wood rotting Basidiomycota native to the South-East Asia. The red pigment from $T$. coccinea fruiting body, which was identified as cinnabarinic acid, showed promising antimicrobial properties against Gram-positive Bacillus subtilis, B. cereus and Gram-negative Escherichia coli. Cinnabarinic acid showed remarkable potential for inhibition of bacterial biofilm formation. As per our knowledge, this is for the first time the inhibition of biofilm formation by cinnabarinic acid has been demonstrated. Further 
investigations will surely unveil the molecular mechanism of biofilm inhibition by identifying the potential targets of cinnabarinic acid in bacterial cells.

\section{Declarations}

Acknowledgment: The authors hereby acknowledge Science and Engineering Research Board (SERB), Department of Science and Technology, New Delhi for providing fund for the present study under the project sanction no. EEQ/2016/000631. The authors are also thankful to the Department of Agricultural Biotechnology and DBT North-East Centre for Agricultural Biotechnology, Assam Agricultural University, Jorhat, Assam for providing laboratory space and facilities for conducting the present study.

Funding: This study was funded by Science and Engineering Research Board (SERB), Department of Science and Technology, New Delhi, India, vide project sanction no. EEQ/2016/000631 without any influence over experimental design, findings and data interpretation.

Conflicts of interest: The authors declare that they have no conflict of interest.

Availability of data: All the necessary data generated through this study are either provided as electronic supplementary information with this manuscript, or those will be available upon conditional request.

Code availability: Not applicable.

Authors' contributions: RCB conceived the idea and acquired funding; MK and RCB designed the study; MK and DJH performed the bioactivities, prepared the figures; MK, SD and DJH performed analytical characterization and data analysis; MK prepared the draft manuscript, MB and RCB provided technical supervision during experimental data generation, analysis and validation; All authors read, critically revised the manuscript and agreed to its content.

Ethics approval: Not needed.

Consent to participate: Not applicable.

Consent for publication: Not applicable.

\section{References}

1. Chen N-H, Liu J-W, Zhong J-J (2008) Ganoderic Acid Me Inhibits Tumor Invasion Through DownRegulating Matrix Metalloproteinases 2/9 Gene Expression. J Pharmacol Sci 108:212-216. doi: https://doi.org/10.1254/jphs.SC00800

2. De Silva DD, Rapior S, Sudarman E, et al (2013) Bioactive metabolites from macrofungi: ethnopharmacology, biological activities and chemistry. Fungal Divers 62:1-40. doi: $10.1007 /$ s13225-013-0265-2 
3. Dembitsky VM, Maoka T (2007) Allenic and cumulenic lipids. Prog Lipid Res 46:328-375. doi: https://doi.org/10.1016/j.plipres.2007.07.001

4. Dullah S, Hazarika DJ, Parveen A, et al (2021) Fungal interactions induce changes in hyphal morphology and enzyme production. Mycology 1-17

5. Eggert C (1997) Laccase-catalyzed formation of cinnabarinic acid is responsible for antibacterial activity of Pycnoporus cinnabarinus. Microbiol Res 152:315-318. doi:

https://doi.org/10.1016/S0944-5013(97)80046-8

6. Eggert C, Temp U, Dean JFD, Eriksson K-EL (1996) A fungal metabolite mediates degradation of nonphenolic lignin structures and synthetic lignin by laccase. FEBS Lett 391:144-148. doi: https://doi.org/10.1016/0014-5793(96)00719-3

7. Eggert C, Temp U, Dean JFD, Eriksson K-EL (1995) Laccase-mediated formation of the phenoxazinone derivative, cinnabarinic acid. FEBS Lett 376:202-206. doi: https://doi.org/10.1016/0014-5793(95)01274-9

8. Fazio F, Lionetto L, Molinaro G, et al (2012) Cinnabarinic Acid, an Endogenous Metabolite of the Kynurenine Pathway, Activates Type 4 Metabotropic Glutamate Receptors. Mol Pharmacol 81:643 LP - 656. doi: 10.1124/mol.111.074765

9. Gao Y, Zhou S, Chen G, et al (2002) A phase I/II study of a Ganoderma lucidum (Curt.: Fr.) P. Karst. (Ling Zhi, Reishi Mushroom) extract in patients with chronic Hepatitis B. Int J Med Mushrooms 4:

10. Gomes FIA, Teixeira P, Azeredo J, Oliveira R (2009) Effect of farnesol on planktonic and biofilm cells of Staphylococcus epidermidis. Curr Microbiol 59:118-122. doi: 10.1007/s00284-009-9408-9

11. Herrmann H (1962) Cortinellin, eine antibiotisch wirksame Substanz aus Cortinellus shiitake. Naturwissenschaften 49:542. doi: 10.1007/BF00626812

12. Hiramatsu R, Hara T, Akimoto $\mathrm{H}$, et al (2008) Cinnabarinic acid generated from 3-hydroxyanthranilic acid strongly induces apoptosis in thymocytes through the generation of reactive oxygen species and the induction of caspase. J Cell Biochem 103:42-53. doi: https://doi.org/10.1002/jcb.21384

13. Høiby N, Bjarnsholt T, Givskov M, et al (2010) Antibiotic resistance of bacterial biofilms. Int J Antimicrob Agents 35:322-332. doi: https://doi.org/10.1016/j.jiantimicag.2009.12.011

14. Jabri SY, Overman LE (2013) Enantioselective Total Syntheses of Plectosphaeroic Acids B and C. J Org Chem 78:8766-8788. doi: 10.1021/j04015479

15. Kakoti M, Hazarika DJ, Kumar A, et al (2021) Genetic Diversity and DNA Barcoding of Wild Mushrooms from Northeast India. Iran J Sci Technol Trans A Sci 45:469-479. doi: 10.1007/s40995021-01067-7

16. Kimyon Ö, Das T, Ibugo Al, et al (2016) Serratia Secondary Metabolite Prodigiosin Inhibits Pseudomonas aeruginosa Biofilm Development by Producing Reactive Oxygen Species that Damage Biological Molecules . Front. Microbiol. 7:972

17. Kozarski M, Klaus A, Jakovljevic D, et al (2015) Antioxidants of Edible Mushrooms. Mol. 20 
18. Lomascolo A, Uzan-Boukhris E, Herpoël-Gimbert I, et al (2011) Peculiarities of Pycnoporus species for applications in biotechnology. Appl Microbiol Biotechnol 92:1129-1149. doi: 10.1007/s00253-0113596-5

19. Luo D-Q, Wang F, Bian X-Y, Liu J-K (2005) Rufuslactone, a New Antifungal Sesquiterpene from the Fruiting Bodies of the Basidiomycete Lactarius rufus. J Antibiot (Tokyo) 58:456-459. doi: 10.1038/ja.2005.60

20. Munita JM, Arias CA (2016) Mechanisms of Antibiotic Resistance. Virulence Mech. Bact. Pathog. 481-511

21. O'Toole GA (2011) Microtiter dish biofilm formation assay. J Vis Exp 2437. doi: 10.3791/2437

22. Ramage G, Saville SP, Wickes BL, López-Ribot JL (2002) Inhibition of Candida albicans biofilm formation by farnesol, a quorum-sensing molecule. Appl Environ Microbiol 68:5459-5463. doi: 10.1128/AEM.68.11.5459-5463.2002

23. Sharma SK, Gautam N (2015) Chemical, Bioactive, and Antioxidant Potential of Twenty Wild Culinary Mushroom Species. Biomed Res Int 2015:346508. doi: 10.1155/2015/346508

24. Singh S, Singh SK, Chowdhury I, Singh R (2017) Understanding the Mechanism of Bacterial Biofilms Resistance to Antimicrobial Agents. Open Microbiol J 11:53-62. doi:

10.2174/1874285801711010053

25. Smânia A, Monache FD, Smânia EFA, et al (1995) Antibacterial activity of a substance produced by the fungus Pycnoporus sanguineus (Fr.) Murr. J Ethnopharmacol 45:177-181. doi: https://doi.org/10.1016/0378-8741(94)01212-I

26. Stewart PS, William Costerton J (2001) Antibiotic resistance of bacteria in biofilms. Lancet 358:135138. doi: https://doi.org/10.1016/S0140-6736(01)05321-1

27. Sullivan G, Henry ED (1971) Occurrence and Distribution of Phenoxazinone Pigments in the Genus Pycnoporus. J Pharm Sci 60:1097-1098. doi: https://doi.org/10.1002/jps.2600600725

28. Suryawanshi RK, Patil CD, Koli SH, et al (2017) Antimicrobial activity of prodigiosin is attributable to plasma-membrane damage. Nat Prod Res 31:572-577. doi: 10.1080/14786419.2016.1195380

29. Tang W, Gu T, Zhong J-J (2006) Separation of targeted ganoderic acids from Ganoderma lucidum by reversed phase liquid chromatography with ultraviolet and mass spectrometry detections. Biochem Eng J 32:205-210. doi: https://doi.org/10.1016/j.bej.2006.09.026

30. Téllez-Téllez M, Villegas E, Rodriguez A, et al (2016) Fungi of Pycnoporus: morphological and molecular identification, worldwide distribution and biotechnological potential. Mycosphere 7:1500

31. Wang H, Ng TB (2006) Ganodermin, an antifungal protein from fruiting bodies of the medicinal mushroom Ganoderma lucidum. Peptides 27:27-30. doi:

https://doi.org/10.1016/j.peptides.2005.06.009

32. Welti S, Moreau P-A, Favel A, et al (2012) Molecular phylogeny of Trametes and related genera, and description of a new genus Leiotrametes. Fungal Divers 55:47-64. doi: 10.1007/s13225-011-0149-2 
33. Wu G-S, Lu J-J, Guo J-J, et al (2012) Ganoderic acid DM, a natural triterpenoid, induces DNA damage, G1 cell cycle arrest and apoptosis in human breast cancer cells. Fitoterapia 83:408-414. doi: https://doi.org/10.1016/j.fitote.2011.12.004

34. Wu T-S, Shi L-S, Kuo S-C (2001) Cytotoxicity of Ganoderma lucidum Triterpenes. J Nat Prod 64:1121-1122. doi: 10.1021/np010115w

35. Xu K, Liang X, Gao F, et al (2010) Antimetastatic effect of ganoderic acid T in vitro through inhibition of cancer cell invasion. Process Biochem 45:1261-1267. doi:

https://doi.org/10.1016/j.procbio.2010.04.013

36. Yue S-J, Song C, Li S, et al (2019) Synthesis of cinnabarinic acid by metabolically engineered Pseudomonas chlororaphis GP72. Biotechnol Bioeng 116:3072-3083. doi:

https://doi.org/10.1002/bit.27118

37. Zhang Y, Wang J, Yajun C, et al (2020) Comparative Genomics Uncovers the Genetic Diversity and Synthetic Biology of Secondary Metabolite Production of Trametes. Mycobiology 48:104-114. doi: 10.1080/12298093.2020.1725361

38. Zhong JJ, Xiao JH (2009) Secondary Metabolites from Higher Fungi: Discovery, Bioactivity, and Bioproduction. In: Zhong JJ, Bai FW, Zhang W (eds) Biotechnology in China I. Advances in Biochemical Engineering / Biotechnology. Springer, Berlin, Heidelberg, pp 79-150

\section{Tables}

Table 1: Antibacterial activity of the $T$. coccinea fruiting body extracts against the test bacterial strains. Zone diameters were represented as mean \pm standard error (SE) of three independent replicates. The letters in superscript denote the levels of significance determined by one way ANOVA with Duncun multiple range test $(p \leq 0.05)$ using SPSS 25.0. 


\begin{tabular}{|c|c|c|c|}
\hline $\begin{array}{l}\text { Sample } \\
\text { name }\end{array}$ & $\begin{array}{l}\text { Test bacterial } \\
\text { strain }\end{array}$ & $\begin{array}{l}\text { Zone diameter ( } \pm \text { SE) at } 1000 \\
\mu \mathrm{g} / \mathrm{ml}(\mathrm{mm})\end{array}$ & $\begin{array}{l}\text { Minimum zone forming } \\
\text { concentration }(\mu \mathrm{g} / \mathrm{ml})\end{array}$ \\
\hline \multirow[t]{3}{*}{ APS1 } & $\begin{array}{l}\text { Bacillus subtilis } \\
\text { SCB-1 }\end{array}$ & $14.00 \pm 0.58^{c}$ & 100 \\
\hline & $\begin{array}{l}\text { Bacillus } \\
\text { cereus S6 }\end{array}$ & $16.33 \pm 0.67^{a}$ & 125 \\
\hline & $\begin{array}{l}\text { Escherichia } \\
\text { coli K12 }\end{array}$ & $15.33 \pm 0.33^{b}$ & 100 \\
\hline \multirow[t]{3}{*}{ APS2 } & $\begin{array}{l}\text { Bacillus subtilis } \\
\text { SCB-1 }\end{array}$ & $12.33 \pm 0.33^{d}$ & 100 \\
\hline & $\begin{array}{l}\text { Bacillus } \\
\text { cereus S6 }\end{array}$ & $14.67 \pm 0.33^{b c}$ & 125 \\
\hline & $\begin{array}{l}\text { Escherichia } \\
\text { coli K12 }\end{array}$ & $14.00 \pm 0.58^{c}$ & 100 \\
\hline \multirow[t]{3}{*}{ F3 } & $\begin{array}{l}\text { Bacillus subtilis } \\
\text { SCB-1 }\end{array}$ & $13.67 \pm 0.33^{c}$ & 125 \\
\hline & $\begin{array}{l}\text { Bacillus } \\
\text { cereus S6 }\end{array}$ & $14.67 \pm 0.33^{b c}$ & 125 \\
\hline & $\begin{array}{l}\text { Escherichia } \\
\text { coli K12 }\end{array}$ & $14.33 \pm 0.33^{c}$ & 100 \\
\hline
\end{tabular}

\section{Figures}

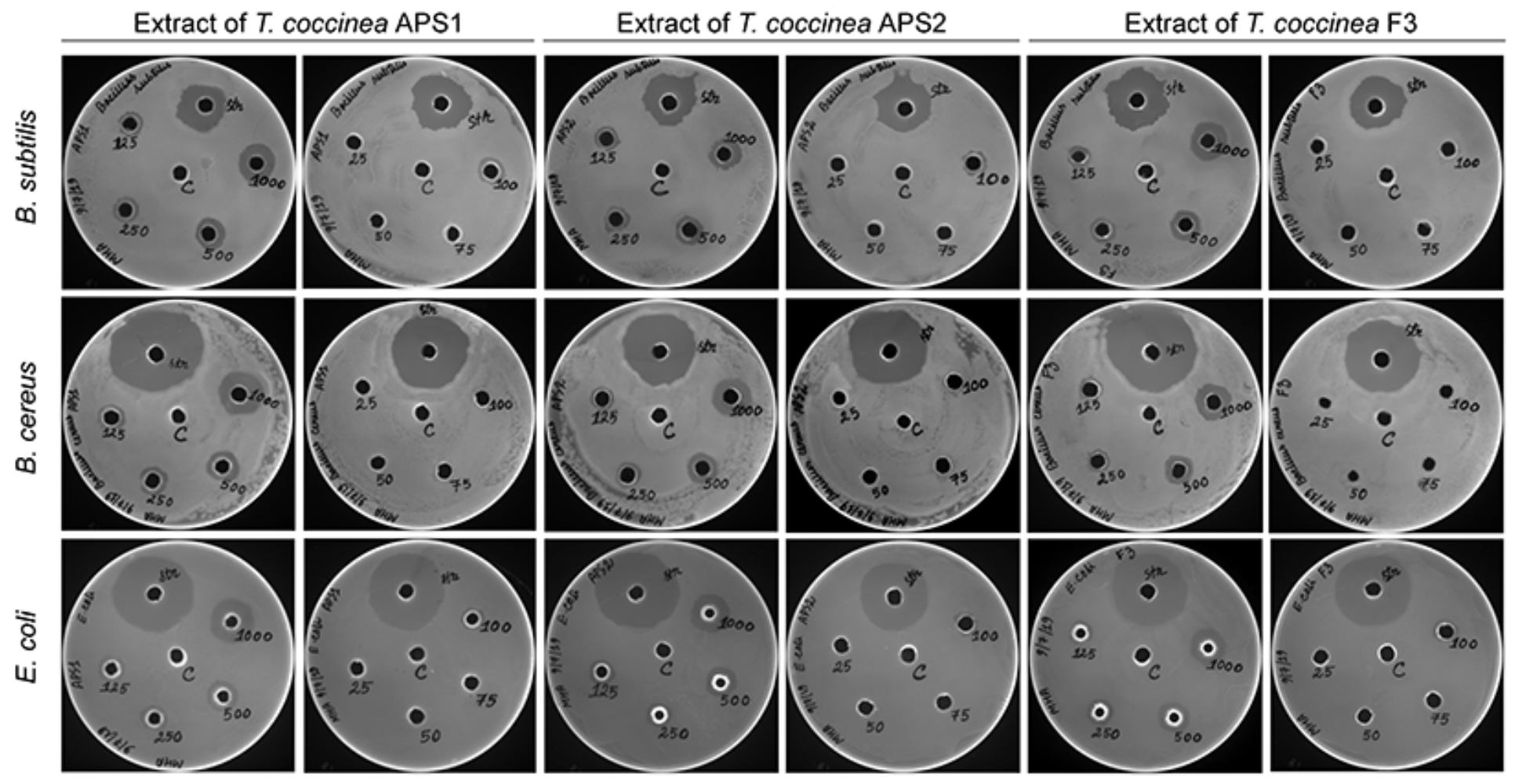


Figure 1

Photographs of plates showing zones of inhibition of the fruiting body extracts against the test bacterial strains. The numbers near each well signify the concentration $(\mu \mathrm{g} / \mathrm{ml})$ of extracts loaded into the respective wells. 'Str' denotes streptomycin $(100 \mu \mathrm{g} / \mathrm{ml})$ used as the positive control in each plate. ' $C$ ' signifies the negative control.
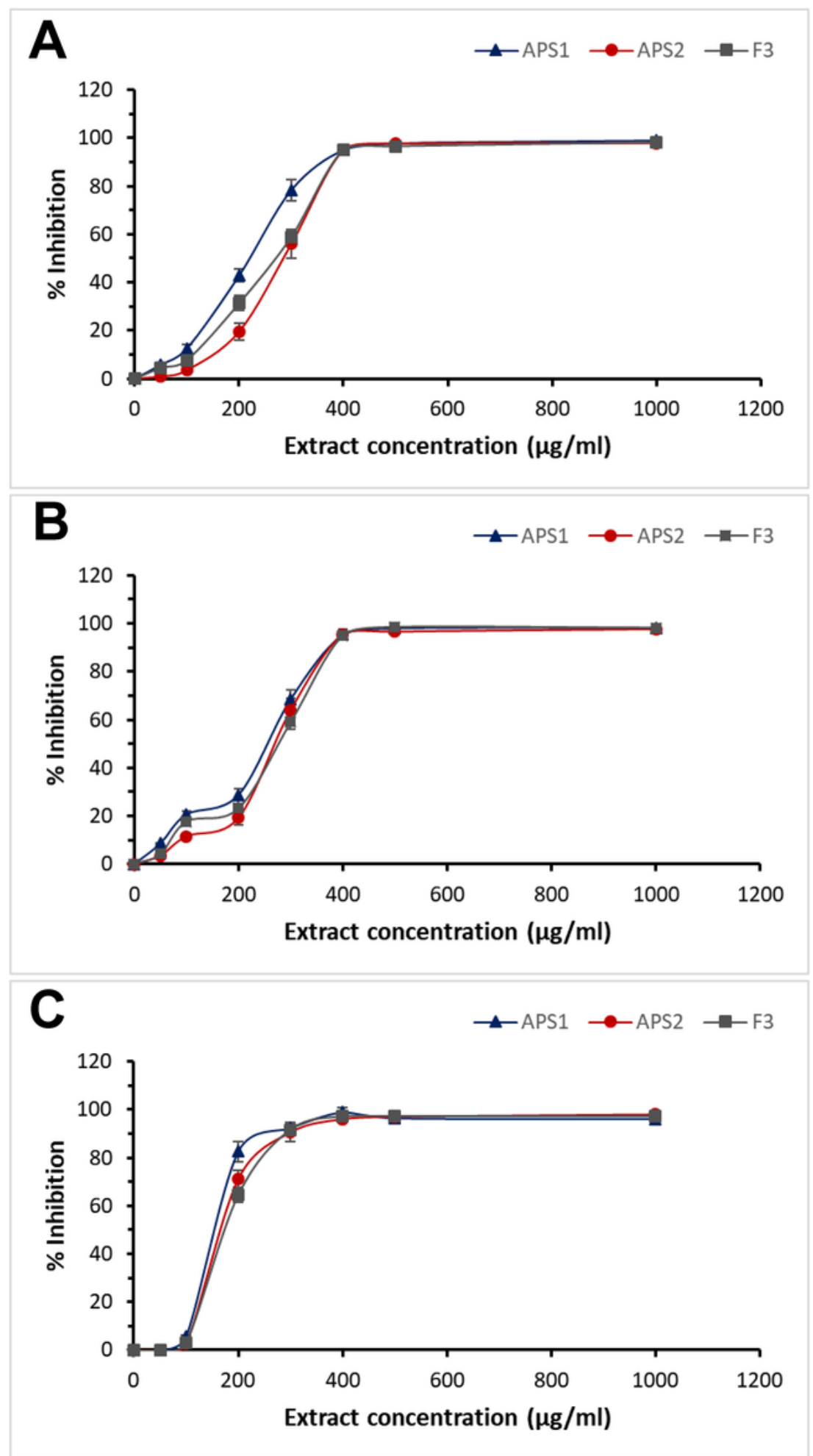

Figure 2 
Minimum inhibitory concentrations of the fruiting body extracts against (A) Bacillus subtilis, (B) Bacillus cereus and (C) Escherichia coli. The MIC was considered to be the concentration that inhibited $>90 \%$ of the bacterial proliferation.
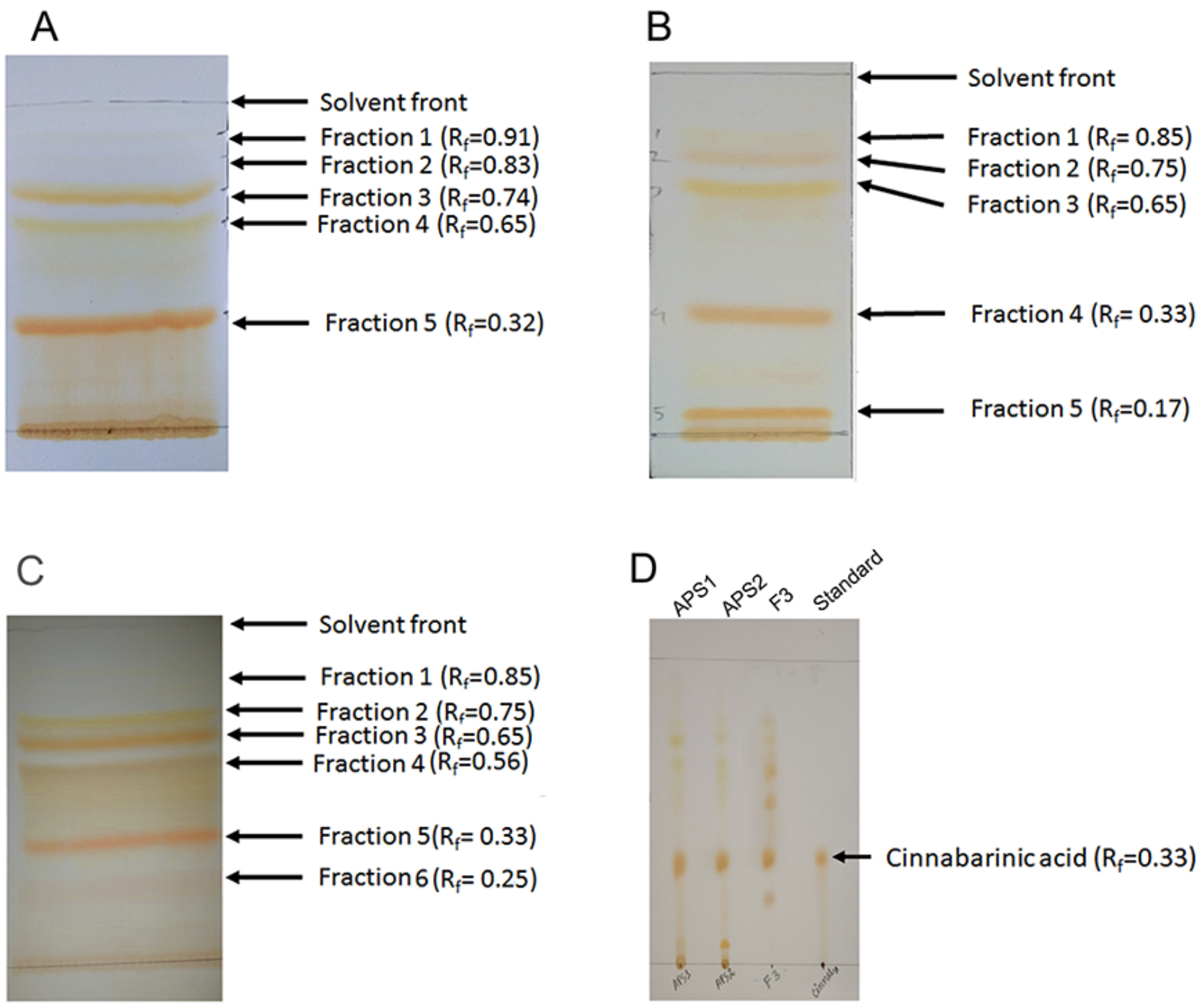

\section{Figure 3}

Thin layer chromatographic separation of the fruiting body extracts of T. coccinea. A. Different fractions present in the crude extracts of T. coccinea APS1; B. Different fractions present in the crude extracts of T. coccinea APS2; C. Different fractions present in the crude extracts of T. coccinea F3; D. Identification of cinnabarinic acid corresponding fraction by comparing with the standard. 


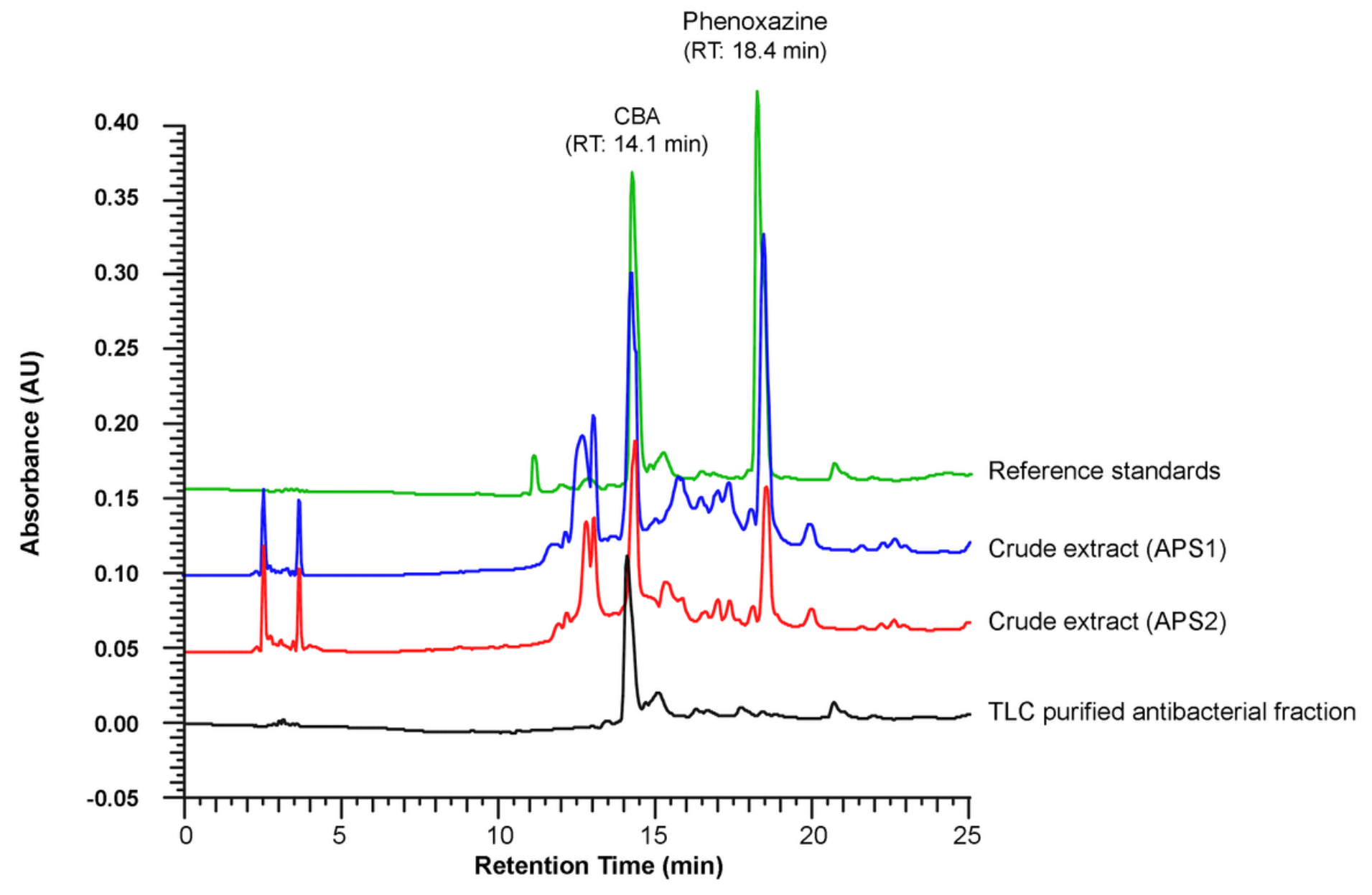

Figure 4

HPLC detection of cinnabarinic acid (CBA) in the crude extracts of T. coccinea and TLC purified bioactive fraction. 


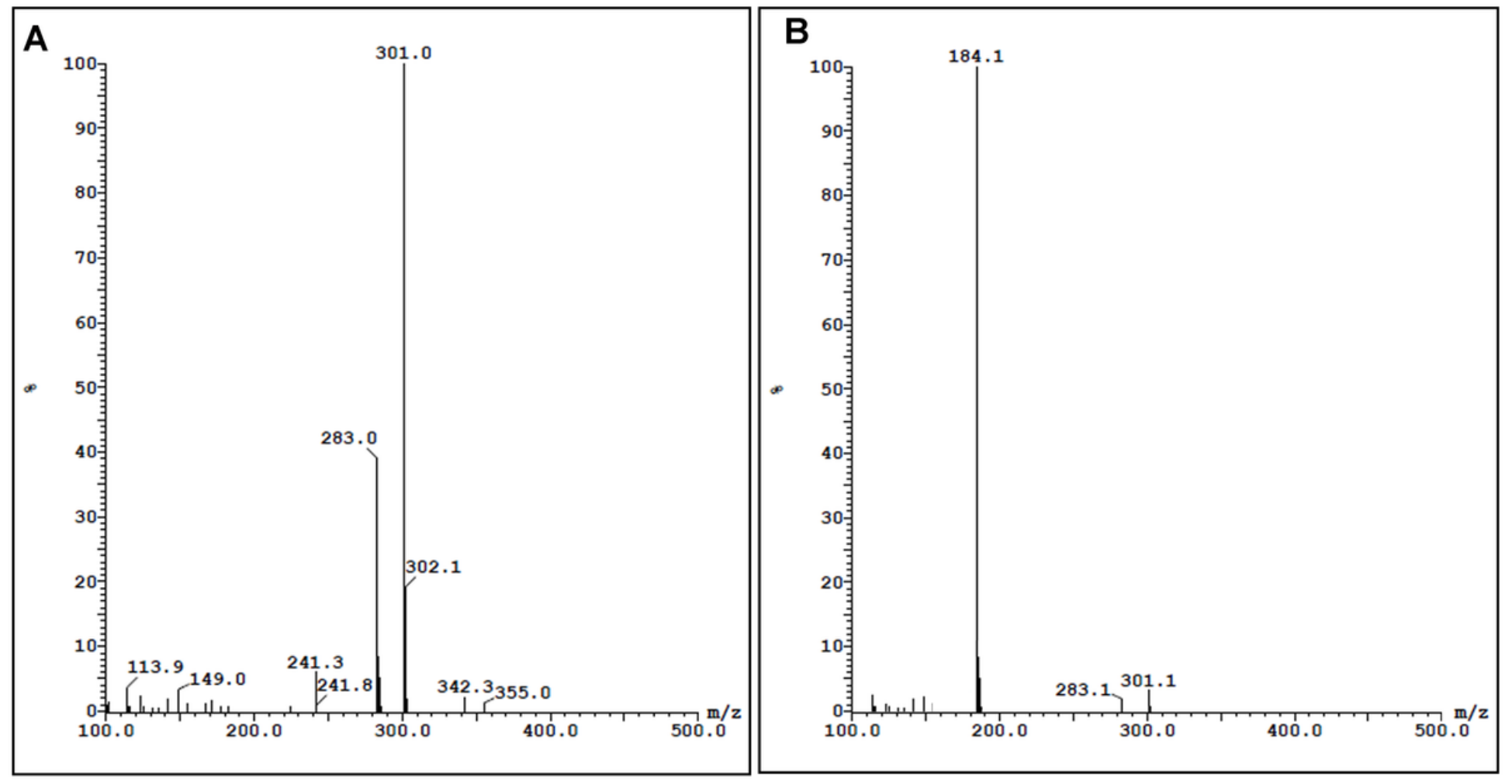

Figure 5

Identification of cinnabarinic acid and phenoxazine purified from the fruiting body extract of T. coccinea using mass spectrometry. A. MS spectra of cinnabarinic acid; B. MS spectra of phenoxazine.

A

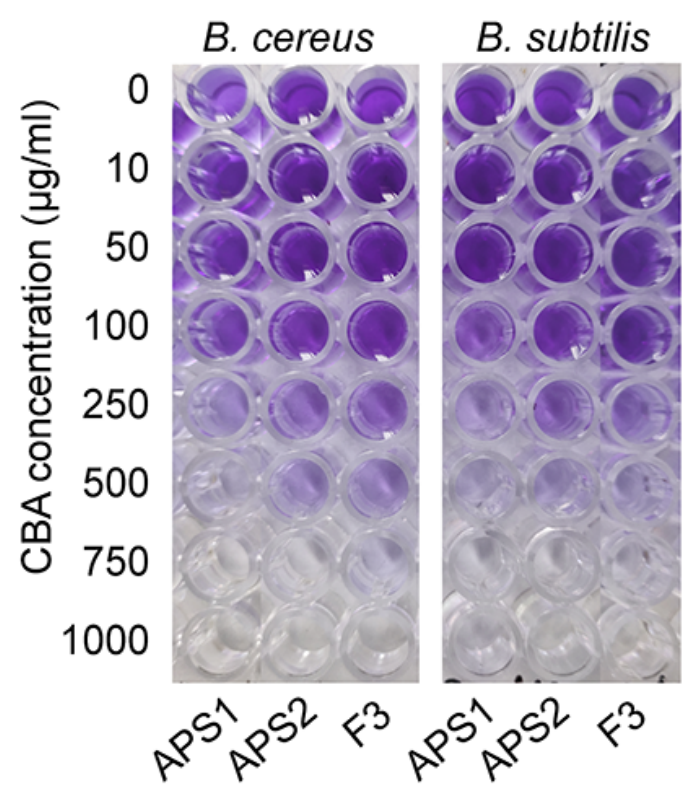

B
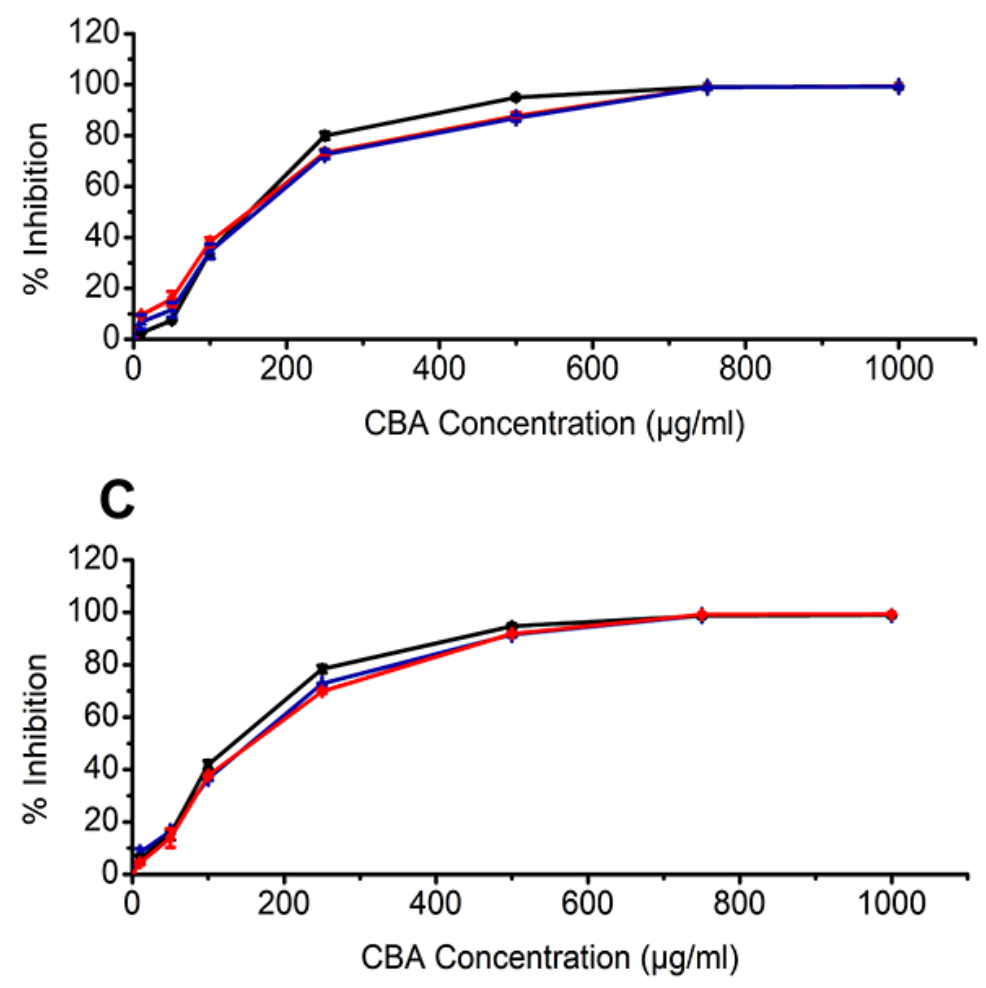
Figure 6

Biofilm inhibitory potential of T. coccinea extracts against biofilm formation in B. cereus and B. subtilis.

A. Photographs showing crystal violet staining of biofilms in microtitre wells after treatment with different concentrations of cinnabarinic acid; B. \& C. Graphical representation of biofilm inhibitory potential of cinnabarinic acid against B. cereus and B. subtilis, respectively.

\section{Supplementary Files}

This is a list of supplementary files associated with this preprint. Click to download.

- SupplementaryInformation.docx 